\title{
RECONSTRUCTING THE LANDSCAPE OF THE PAST IN THE AGRICULTURAL TERRACES OF THE CITY OF AVDAT
}

\author{
Reuma Arav, ${ }^{1, *}$ Sagi Filin, ${ }^{1}$ Yoav Avni ${ }^{2}$ \\ ${ }^{1}$ Mapping and Geoinformation Engineering, Haifa, Israel - (reumaa, filin)@ technion.ac.il \\ ${ }^{2}$ Geological Survey of Israel, Givat Ram, Jerusalem - yavni@gsi.gov.il
}

Commission II, WG II/8

KEY WORDS: Ancient agricultural terraces, Landscape reconstruction, Laser scanning, Photogrammetry, Avdat

\begin{abstract}
:
Large areas in the arid Southern Levant are dotted with ancient agricultural terraces and runoff harvesting installations. In the Negev Highlands, Israel, they were constructed in the 3rd-4th centuries CE, maintained for 6-7 centuries, and then abandoned after the 10th century. Their design pattern and foundations provide a rare insight to the prevailing environmental conditions during the middle Holocene, while their 600-700 years cultivation tells the story of their maitainance and desert agriculture in these regions. From their abandonment onwards, they documented more than 1000 years of land degradation and soil erosion till present time. In this paper, we follow a complete cycle of desert agriculture of two sites near the UNESCO world-heritage town of Avdat. We reconstruct the landscape at the period pre-dating the first anthropogenic intervention, through the centuries of cultivation, and into a millennium of abandonment until the present erosion phase. We use high-resolution 3-D data to document the erosion and environmental dynamics during these two millennia, and to compute rates of siltation and erosion. Long-term measures of such kind are unique, as it is rare to find a millennium-scale documentation of soil erosion processes. Their study improves our understanding of the long-term environmental change mechanism acting in arid environments. The detailed analysis of these installations also offers insights into methods for soil conservation, for sustainable desert inhabitation, and for strategies to protect world-heritage installations. As the globe-wide struggle to combat soil erosion becomes urgent, this case study becomes even more relevant.
\end{abstract}

\section{INTRODUCTION}

The arid Southern Levant is one of the few regions, worldwide that contains undisturbed evidence of agricultural installations from ancient times that were irrigated by runoff harvesting techniques. In the Negev Highlands, an arid region in southern Israel, these installations were constructed mainly between the 3rd-4th centuries CE and cultivated for 600-700, years until their abandonment in the 10th century (Avni et al., 2006, 2012; Faershtein et al., 2016). They comprise of an elaborate set of agricultural and hydrological installations including stone made dams, diverting channels, and agricultural terraces and plots (Avni et al., 2012, 2013; Haiman, 2012). Examination of these installations provides a rare opportunity to study natural and anthropogenic-induced influences over almost two millennia. Using well preserved installations, we demonstrate in this paper how use of 3-D data acquisition technologies and advanced processing methods is not only imperative for site documentation but also sheds light on the entire life cycle of these systems and on the environmental change within the region, a typical arid environment of the Southern Levant.

Two demonstrative installations that lie in the vicinity of the ancient desert town of Avdat, a world-heritage UNESCO site, are the focus of this study. The first is a small agricultural terrace that witnessed colossal damage to part of its retaining wall, and the second is a complex set of agricultural terraces at the outlet a side tributary of the Avdat wadi. The latter site benefited from a greater supply of runoff and led to a different construction process. Following its abandonment, it was affected by an incision of a deep gully, and hence offers different insights and challenges. Both sites document all three life-cycle phases:

\footnotetext{
*Corresponding author
}

their primer natural configuration prior to human intervention, followed by the construction, cultivation and maintenance of the agricultural installations, and the erosion that followed their abandonment. They document centuries of cultivation as well as millennium time-scale of natural processes. Their examination, through their evolutional phases, provides a unique opportunity to study about desert societies as well as on natural and anthropogenic-induced environmental changes of the past 2,000 years.

\subsection{The Avdat agriculture installations}

The city of Avdat is a UNESCO World Heritage site, part of the four Nabatean desert towns along the Incense Route in the Negev Desert. Within its vicinity lie large agricultural systems, which served the people of the city (UNESCO, 2013). These systems were abandoned with the desertion of the city, forsaking them to the destructive forces of the desert.

Our study focuses on two representative sites within the surrounding of the ancient city (Fig. 1a). Both sites are located next to Nahal Avdat, a side tributary of the main Nahal Zin stream that runs through the Negev highlands to the Dead Sea, draining an area of $\sim 1000 \mathrm{~km}^{2}$ (Fig. 1b). The two sites are typical representatives of the runoff-harvest agriculture: the first demonstrates runoff installations while the second is a set of tall terraces and stone dams holding deep soils, constructed directly along the water courses of minor drainage basins or along the uplifted banks of major streams.

Site \#I (Fig 2a), is a single agricultural plot, located $\sim 2 \mathrm{~km}$ west of the city, on the northern bank of Nahal Avdat. The bank and the terrain to the north of the main-stream channel are 

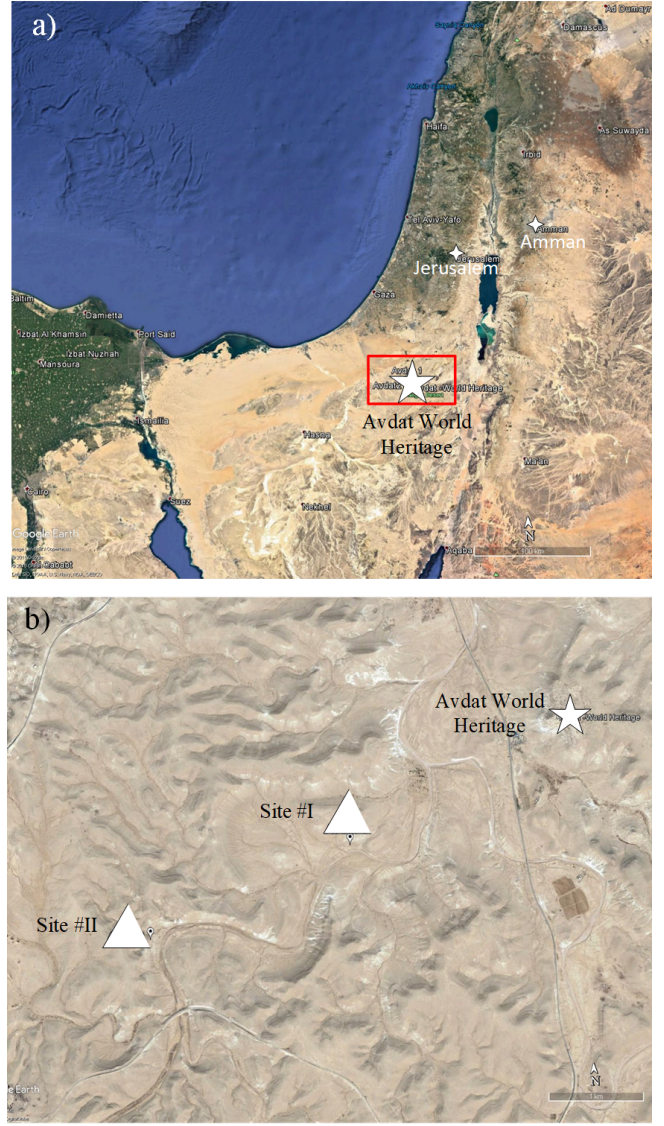

Figure 1. Study sites and the city of Avdat.

covered by a shallow section of loess sediments integrated with local gravels, forming a relatively flat strip of land sandwiched between Nahal Avdat channel and the steep hills of the Avdat Plateau.

Site \#II (Fig 2b) is located upstream Nahal Avdat, about $5 \mathrm{~km}$ west of the city. The site comprises of nine high agricultural terraces, of which four damaged by the incision of the gully. The relatively shallow topography, availability of runoff that flows down the tributary, and the wide area covered by loessic soil with agricultural potential are most likely the reasons for the construction of this dense set of agricultural terraces at this location.

\subsection{Runoff harvesting}

The techniques applied in these farms were based on runoff diversion from the hillsides and main channels during heavy rains and floods and into the agriculture fields. Each plot was bordered by a constructed stone walls that trapped the floodwater. This type of runoff installations was designed for trapping large quantities of flood water, allowing a deeper infiltration of water. Runoffs entered agricultural plots directly through gully water course or via diverting channels from nearby streams. Such plots were used mainly for cultivating grape and olive orchards (Avni et al., 2019). The deep water storage was necessary for fruit production during the long dry summers and for survival throughout multi year droughts.

Besides irrigation, this technique led to accumulation of fine sediments carried by the water, and to gradual siltation of the plots. As silt accumulated, the farmers occasionally had to add a course of stones to wall, in order to provide space for irrigation water. Over time, this process led to the formation of terraces up to eight to twelve courses high (Fig. 5a) protecting fine sediments that could accumulate to up to $2.5 \mathrm{~m}$ height. Optically stimulated luminescence (OSL) ages indicate that maintenance of the farms was sustained for at least 700 years (Avni et al., 2006). This is supported also by archaeological record that shows that they functioned continuously for several hundred years during the Byzantine and Early Islamic periods.

\subsection{Project scope}

Documentation of both sites poses a challenge, both because of their span and the different levels of detail needed for the various aspects of the study. We combine in our study close-range photogrammetry and high-resolution laser scans, both static and hand-held, for documenting and studying the two sites.

Each technology offers different type of data, together compiling the whole site. Static laser scans are cardinal to document the erosion, which in some cases can amount to a few centimeters of gully headcut migration. The hand-held scanning data allows efficient yet detailed recording of the surrounding topography, while photogrammetric imaging enriches the acquired data with radiometric information for focused and detailed documentation of the walls.

Measurements were taken over a period of five years, as a means to provide detailed characterizations of features and patterns of destruction on a century-to-millennium-scale, and to analyze structural elements and building materials for constructions. The spatial distribution and dimensions of the buildingstones when analyzed, reveals maintenance procedures for the terraces that were prone to occasional collapse of some parts of the structures.

Furthermore, acquisition of the overall surrounding topography allows us to develop means for reconstruction of the natural environment prior to the plots foundation, and to evaluate their impact on the environment. The recorded fluvial terraces provide markers to the topography of the valleys at time of construction, thus enables surface repair of that time. Moreover, the top of the agricultural terraces documents the topography at the time of abandonment, allow a second reconstruction of the topography, $\sim 700$ years later. Hence, with the data acquired we can reconstruct the site at time of development, through its 700 year of cultivation and maintenance, and lastly, through its destruction phase since abandonment.

\section{DATA ACQUISITION}

The combination of different sensing techniques document both detail and general features within the topography. Therefore, they provide an excellent means to characterize the natural environment prior to the plots construction and to evaluate their impact on the environment, while also enable specific analysis of man-made features. Furthermore, erosion since abandonment is also made available, providing a minute characterization of features and patterns on a century-to-millennium-scale. The repeated measurements allow the computation of volumes, present erosional rates, which are comparable to long-termrelated measurements. 

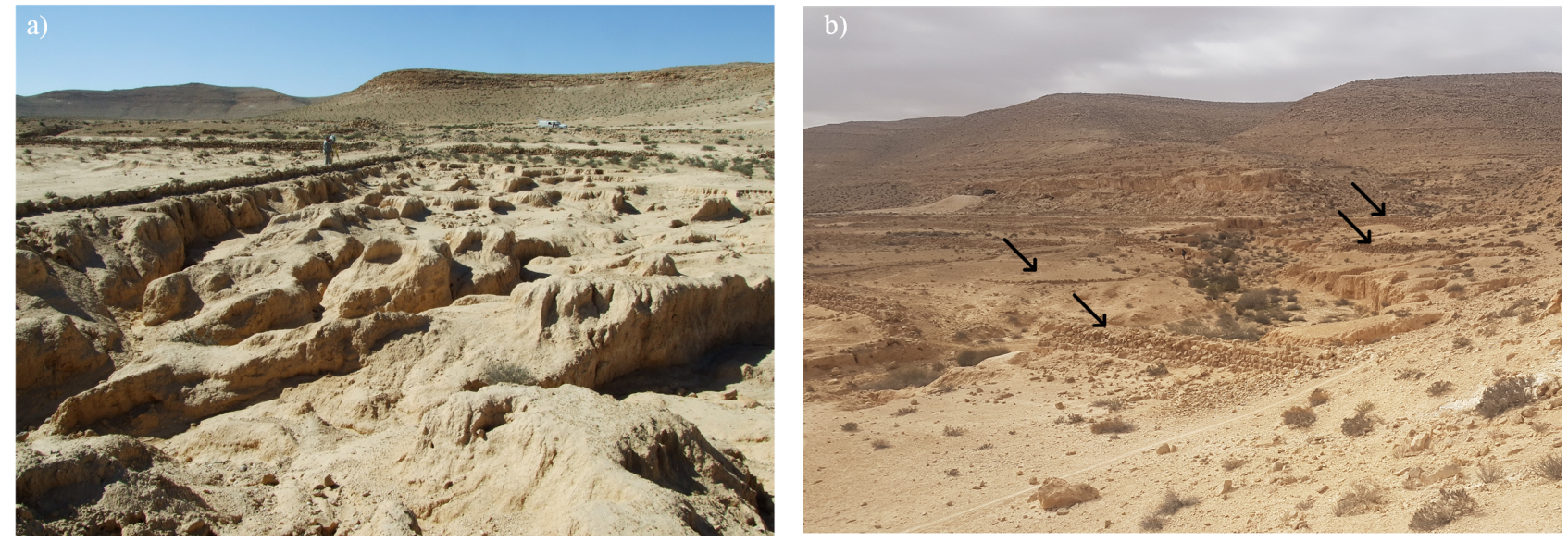

Figure 2. Images of the study sites: a) Site \#I - look to the northwest corner; b) Site \#II - an overview of the site with terraces marked by black arrows.

\subsection{Terrestrial laser scans}

Both sites were documented over a five-year period, from 2012 until 2017, using the Leica ScanStation c10 whose surface measurement accuracy is $\pm 2 \mathrm{~mm}$ and angular measurement accuracy is $\pm 12 "$. Vertical and horizontal angular resolution was approximately $0.057^{\circ}$, with each scan consisting of 7 million points on average, spanning $360^{\circ}$ horizontally and $90^{\circ}$ vertically. Six to ten scans were made around each site to secure complete coverage (technical details of each scan are summarized in Table 1). The focus of the repetitive scans was recording the migraton of the headcuts, and as the gully incision leads to complex terrain, several posts, surrounding the head, were necessary to secure complete coverage. The highresolution data document the structure and shape of the original plots and captures minute details from the man-made structures.

As the topographic reconstruction is carried at centimeter-scale, the surrounding topography does not require a millimeter-scale documentation. Hence, farther areas, which are imperative for the scene completeness but are not subjected to erosion analysis, such as neighboring terrace structures and the surrounding topography, were documented by GeoSLAM ZebRevo, whose relative accuracy is $1-3 \mathrm{~cm}$. Its angular resolution is $0.625^{\circ}$ horizontally and $1.8^{\circ}$ vertically.

The individual scans acquired by the terrestrial laser scanner, in each campaign, were combined into a unified set by deployment of designated reflector targets. Their utilization led to a registration accuracy of $\pm 2 \mathrm{~mm}$, or better. As placement of such artificial targets within the site on a project-long basis was not optional, a cloud-based registration approach was applied to link between-campaign scans and between the scans acquired via the ZebRevo scanner. Here, fixed elements within the site acted as anchor entities, and single scans were aligned between epochs using the Visual Alignment tool in Leica Cyclone Register v9.3.2. Accuracy of the co-registration was $\pm 5 \mathrm{~mm}$ for the Leica ScanStation c10 scans and $\pm 15 \mathrm{~cm}$ for the GeoSLAM ZebRevo.

\subsection{Photogrammetric imaging}

To enrich the reconstruction of the walls, images were acquired using a Nikon D70 camera with a Nikkor 24 lens. Image orientation and modeling was performed using the Pix4D software v4.4 (Pix4D S.A., 2019), while scaling and referencing was
Table 1. Laser scanning acquisition details.

\begin{tabular}{c|ccc} 
Epoch & \# of scans & $\begin{array}{c}\text { Site \#I } \\
\text { \# of points } \\
\text { (Millions) }\end{array}$ & $\begin{array}{c}\text { point density } \\
\left(\mathrm{pts} / \mathrm{m}^{2}\right)\end{array}$ \\
\hline 2012 & 5 & 25.3 & 7,800 \\
2013 & 6 & 30.0 & 5,500 \\
2014 & 13 & 35.7 & 6,100 \\
2015 & 11 & 40.1 & 5,900 \\
2016 & 10 & 12.6 & 7,100 \\
2017 & 9 & 17.7 & 8,500 \\
ZebRevo & 2 & 13.8 & 2,800 \\
\hline \hline & & Site \#II \\
2012 & 5 & 45.6 & 6,000 \\
2013 & 4 & 9.5 & 6,200 \\
2014 & 9 & 40.6 & 5,200 \\
2015 & 6 & 37.4 & 5,100 \\
2016 & 10 & 19.8 & 5,000 \\
2017 & 8 & 21.6 & 5,500 \\
ZebRevo & 2 & 9.5 & 2,900 \\
\hline
\end{tabular}

performed with respect to data derived from the laser-scans. The photogrammetric images document the maintenance procedures carried by the farmers through the $\sim 700$ years of utilization. Their incorporation with the laser scans enable to identify environmental-related elements, like the sedimentary interface between the Pleistocene-Holocene fluvial sediments and the anthropogenic induced soils accumulated within the installations.

\section{STRUCTURAL CHARACTERIZATION}

Structural characterization is carried by general description of each site. Detailed documentation of the walls included dimension measurements of the building-stones (width and height) and statistical analysis was made regarding dimensions and spatial distribution. This was carried at designated sections of the walls, using both photogrammetric measurements and laser scanning, where maintenance work was apparent. Volume of the plots was computed for soil aggradation and erosion. To compute the volume of entrapped sediment the level of the buried fluvial had to be reconstructed. Using section-lines recovered in incised areas within the terraces, where the foundations of the wall are visible, the baseline was set for initial elevation of the soil at time of construction (Fig. 5b). The volume was then estimated via area of each plot times the times the elevation difference between the fluvial terrace baseline to that of the top of the agricultural one. Soil loss volume since abandon- 


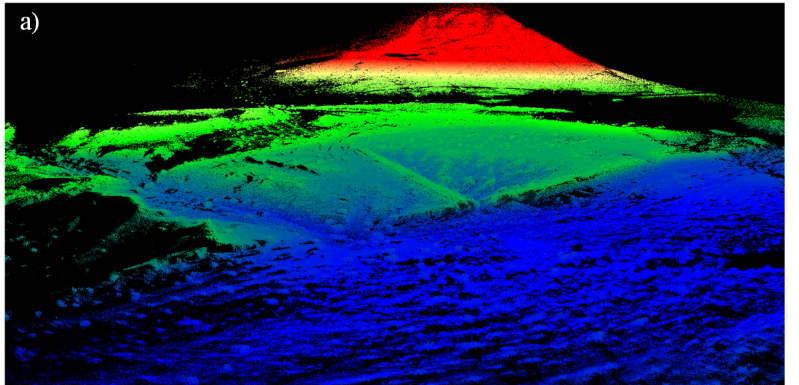

Elevation $[\mathrm{m}]$

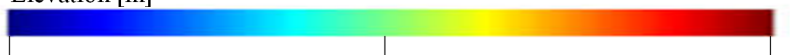

$0-$ Stream elevation $4.5 \mathrm{~m}$

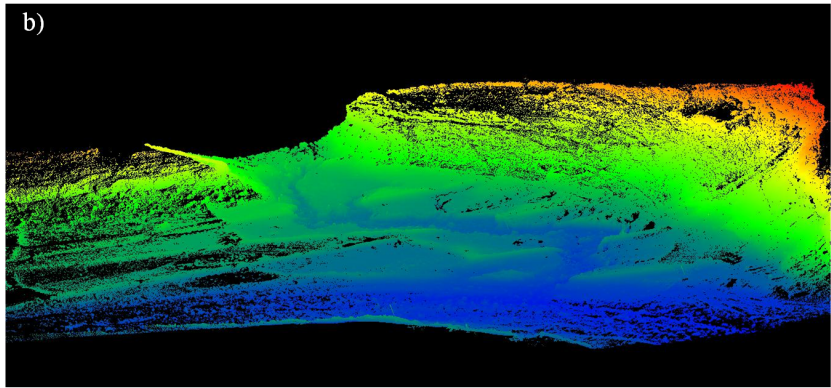

Elevation $[\mathrm{m}]$

Figure 3. Scene documentation via laser scans of Site \#I. a) Point cloud acquired by one static terrestrial position; b) Point cloud acquired by both hand-held and static terrestrial scans.

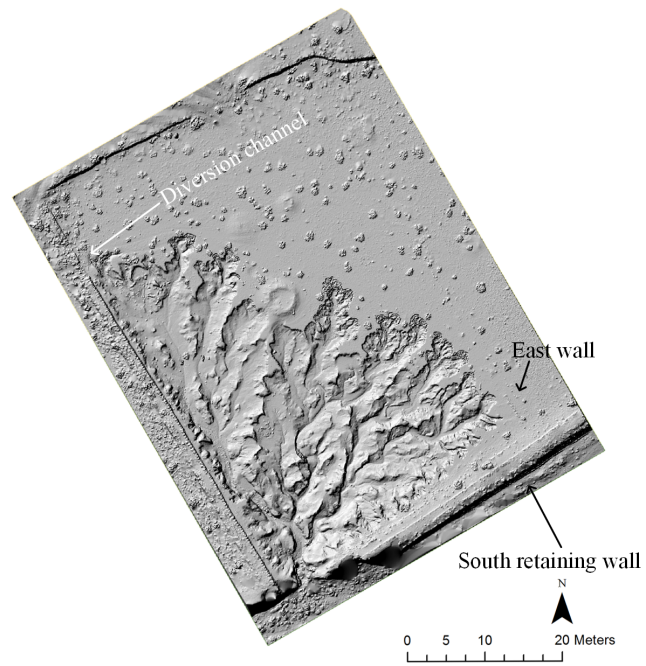

Figure 4. Site \#I: Hillshade focusing on the plot.

ment was measured via polyhedral volume summation (Arav et al., 2015).

\subsection{3-D characterization of Site \#I}

Site \#I is a single, roughly rectangular plot, $60 \times 38 \mathrm{~m}^{2}$ (Fig. 4). Four walls define the plot's borders. At the south border, a massive retaining wall that separates the plot from the Avdat stream (Fig. 5a). It was constructed on top of a remnant of a natural fluvial terrace, with foundations laid in a $20-30 \mathrm{~cm}$ deep trench dug within the fluvial terrace (Fig. 5b). The wall rises to a height of $\sim 3.4 \mathrm{~m}$ above the channel bed and its cap is $1.4 \mathrm{~m}$ wide. Its outer face, towards the stream, is made of 7-12 distinct layers of large rectangular-cut blocks, $40 \times 30 \mathrm{~cm}$ on average (Fig. 5c). The inner face is built of smaller building stones $20 \times 10 \mathrm{~cm}$ (Fig. $5 \mathrm{~d}$-e). The gap between the two faces is filled with $\sim 3 \times 5 \mathrm{~cm}$ small gravels, aimed to provide strength and flexibility. Notably, another row of stones can be found in parallel to the wall, apparently related to water channeling and irrigation. Sharp changes are noticeable in stonework and block size at the upper parts of the south retaining wall (Fig. 5a). The wall's inclination is $20^{\circ}$ or less at its base, changing to $40-60^{\circ}$ at its higher sector (Fig. 6). The western wall separates the plot from its neighbor (Fig. 6a). It is $0.5 \mathrm{~m}$ high and $1.5 \mathrm{~m}$ thick (Fig. 5c) and is constructed of two rows of 35-40 $\mathrm{cm}$ long building-stones. The space between the two rows is
Table 2. Terraces area in Site \#II

\begin{tabular}{cc} 
Terrace & Area $\left[\mathrm{m}^{2}\right]$ \\
\hline I & 2995.43 \\
II & 4352.17 \\
III & 3205.35 \\
IV & 3123.17 \\
\hline
\end{tabular}

also filled by small gravels $(3 \times 5 \mathrm{~cm})$. A north wall separates the plot from the hill-slope. It is $0.7 \mathrm{~m}$ high, $0.5 \mathrm{~m}$ thick and is built of $\sim 25 \times 12 \mathrm{~cm}$ long stones (Fig. 6b). The eastern boundary wall is marked by two partially buried rows of stones of the same size, approximately $1.0 \mathrm{~m}$ wide (Fig. 6c). Measurement of the elevation difference between the top of the fluvial terrace to that of the agricultural one yields $\sim 1 \mathrm{~m}$, implying that the accumulated sediment throughout the cultivation period amounts to $2,200 \mathrm{~m}^{3}$.

\subsection{3-D characterization of Site \#II}

Nine agricultural plots define the site. Four of them were dissected by a tributary of the Avdat stream, enabling to analyze their construction, and are the focus of this stduy (Fig. 7). Their foundations are dug into the sediment, where two rows of $\sim 60 \times 40 \mathrm{~cm}^{2}$ blocks are laid. Shape-wise, the agricultural plots conform to the natural bend of the land prior to their construction. Hence, their areas vary from $\sim 3,000 \mathrm{~m}^{2}$ to $\sim 4,350 \mathrm{~m}^{2}$ (Table 2). A system of diverting channels harvests runoff from the main tributary and from the nearby rocky slopes to irrigate the plots. The in-farm runoff distribution is implemented by spillways that channel irrigation water from one plot to another.

The laser data show that the agricultural terraces' walls are composed of 8 to 10 layers of stacked building-stones, 35$25 \mathrm{~cm}$ long, near rectangle shaped, with no cement added. They create 1.5-2 m high and 0.5-1.5 m wide structures, composed of two parallel rows of building-stones filled with gravels. The lowermost terrace wall, which is in direct contact with the Avdat stream is completely ruined, except for a $28 \mathrm{~m}$ damaged part. A total volume of $22,280 \mathrm{~m}^{3}$ sediments are stored within the terraces. About half of the sediment is of the natural preagriculture floodplain, whereas the rest was accumulated during the cultivation period.

\section{EROSION DOCUMENTATION}

Long- and short-term soil losses are cardinal parameters to evaluate the destructive process these plots underwent since abandonment and the current trend the undergoing. Annual erosion 


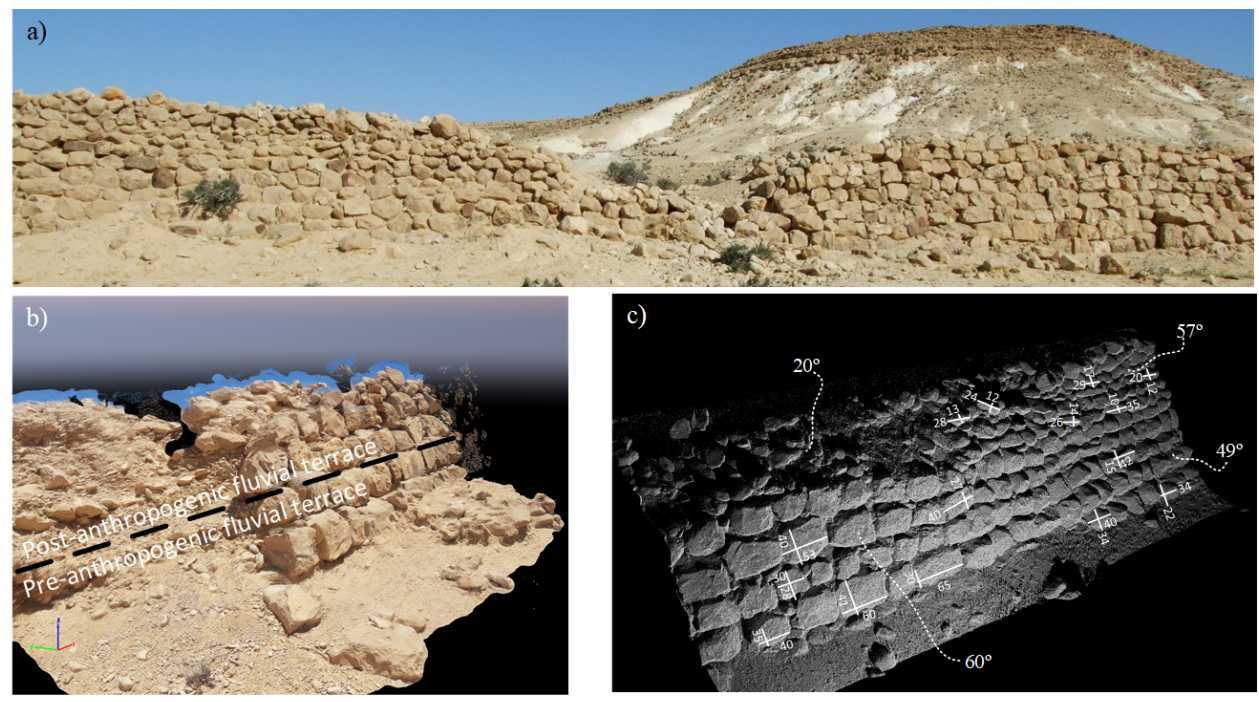

Figure 5. Analysis of the retaining wall in Site \#I.
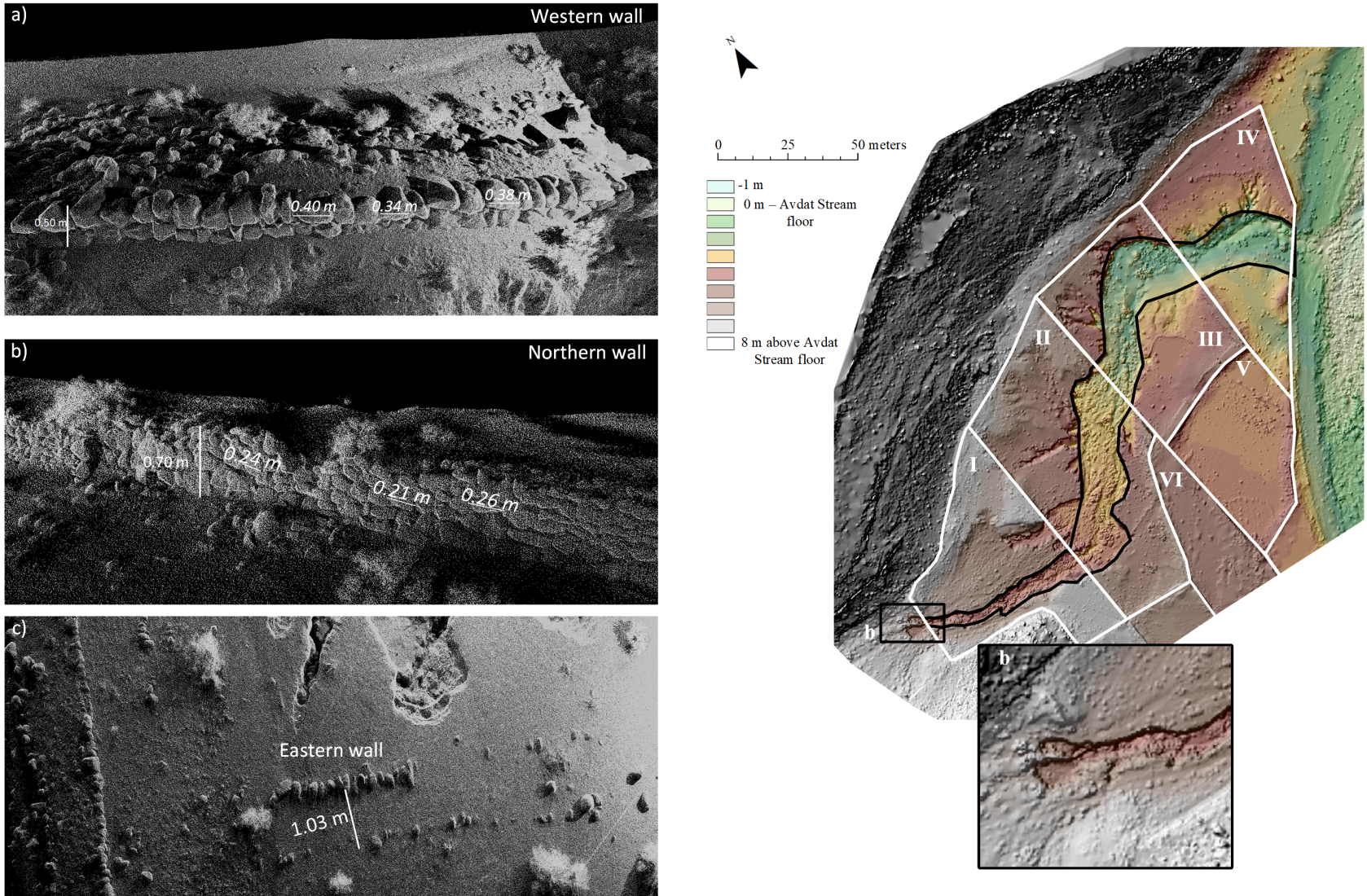

Figure 6. Detailed description of the walls around Site \#I.

Figure 7. Hillshade view of Site \#II - terraces and gully 


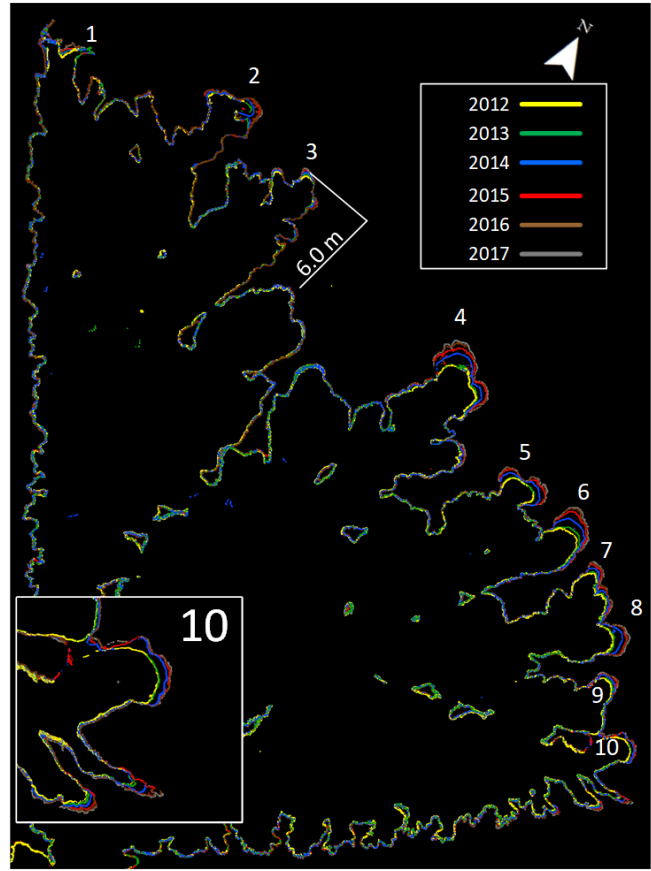

Figure 8. Measurement of gullies in Site \#I

was measured by two parameters: longitudinal expansion and soil loss volume, annually. The longitudinal difference between epochs was measured at the head of each gully. To ensure that the head's development is measured horizontally, and to avoid misinterpretation of the 3-D data, a $10 \mathrm{~cm}$ slice, aligned with the $\mathrm{X}-\mathrm{Y}$ axes, was extracted from the epoch-registered point clouds at an elevation of $0.15 \mathrm{~m}$ below the plot surface, using Leica Cyclone 9.3.2 cutplane tool. Lengths were measured according to the direction of the head's development. The annual soil loss rate was carried at gully heads, from where most soil is removed in the short term. Due to the complexity of the erosive pattern within the gully, soil-loss volume was measured first by delineation of the new eroded part at the head, and then by computation polyhedral volume summation (Arav et al., 2015).

\subsection{Soil loss - Site \#I}

The eroded soil from the entire plot is measured at $733 \mathrm{~m}^{3}$ and amounts to $35 \%$ of the accumulated soil over the cultivation period. The gully system forms an approximately uniform radial pattern. Their length decreases almost consistently from $47.9 \mathrm{~m}$ at the west wall to $34.5 \mathrm{~m}$ at the south (Fig. 8). The five years of monitoring show that their annual head expansion ranges $5-30 \mathrm{~cm}$. These rates increase gradually from both plot ends, toward the center (Fig. 8). Observations show that the central region is enjoying a greater supply due to modern interference along the northern. While the average retreat rate was measured at $14 \mathrm{~cm} / \mathrm{yr}$, normalizing the extreme rates at the plot center, brings it to $9 \mathrm{~cm} / \mathrm{yr}$. Volumes of eroded soil yield an average removal rate of $1.21 \mathrm{~m}^{3} / \mathrm{yr}$, and following normalization it becomes $0.63 \mathrm{~m}^{3} / \mathrm{yr}$.

\subsection{Soil loss - Site \#II}

As in Site \#I, destruction of the outermost retaining wall initiated a gully at the edge of the lowermost plot. Its length is $245 \mathrm{~m}$ and its breadth is $20 \mathrm{~m}$ at its lower segment, becoming narrower upstream, reaching 2-4 $\mathrm{m}$ and ending with two

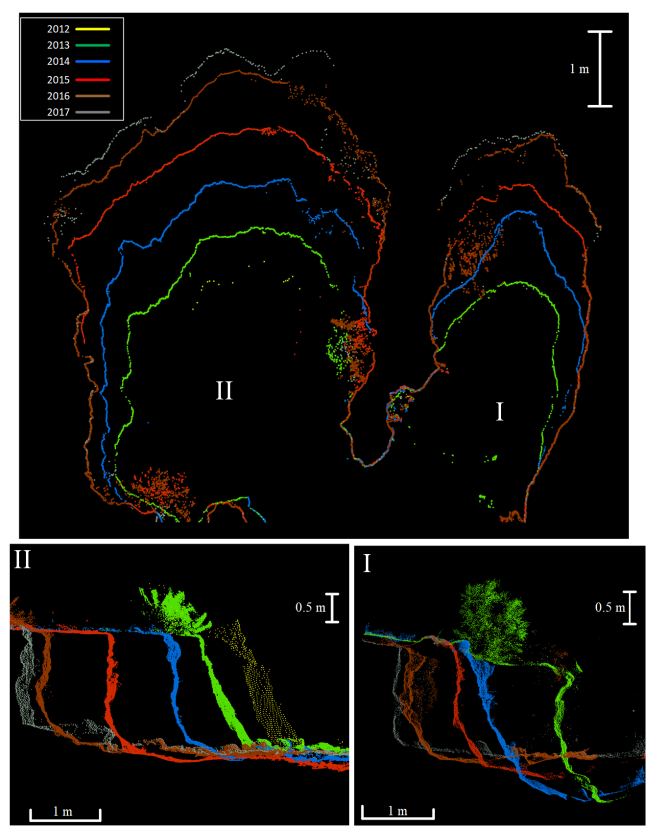

Figure 9. Measurement of headcut migration in Site \#II: top-view of the slice; I, II) side-view of the heads.

distinct headcuts (Fig. 7). The total eroded sediment is measured at $9,860 \mathrm{~m}^{3}$, where $6,192 \mathrm{~m}^{3}$ of this volume was contributed by the main gully. The annual retreat of each of the two heads, during our monitoring period is uneven (Fig. 9) and varies between $0.13-1 \mathrm{~m}$. It is a function of the seasonal runoff yield, flood parameters, and the location of micro-channels that divert floodwater to each of the heads (Zweig et al., 2018). The four plots lost $\sim 45 \%$ of the $22,280 \mathrm{~m}^{3}$ anthropogenic stored sediment. The average volume loss rate during our monitoring period is $5.54 \mathrm{~m}^{3} / \mathrm{yr}$.

\section{LANDSCAPE RECONSTRUCTION}

Reconstructions of the topography prior to the anthorpogenic intervention and at time of abandonment are feasible due to the gullies incision that discovered the terraces foundations and the interface between the old fluvial terrace and the newly aggregated soil. The baseline used for volume estimation (cf. Sec. 3) was used here to define the past topography, in conjunction with the surrounding hills.

\subsection{Time of construction}

As the first stage of preparation of the arable land for cultivation in the 3rd-4th century, the farmers had to protect the friable sediments (loess) which dominated the area (such practices are also reported by Londoño et al. (2017), from agricultural terraces of the Wari culture in Southern Peru). By removal of the aggregated loess during cultivation-time, from the baseline upwards, we can reconstruct the mid-Holocene paleo-surface. In both sites, cut-planes were used in Cyclone to reveal the primer topography, followed by the construction of planar surfaces according to the remaining topography within Autodesk 3ds Max 2018. These planes were consequently subsampled using AWS Thinkbox Krakatoa MX 2.9 plugin to comply with the terrestrial scans resolution and provide a scanned scene visualization.

In Site \#I, a cut-plane was constructed from the topmost visible foundation stones, along the wall and up to the foothill at the 


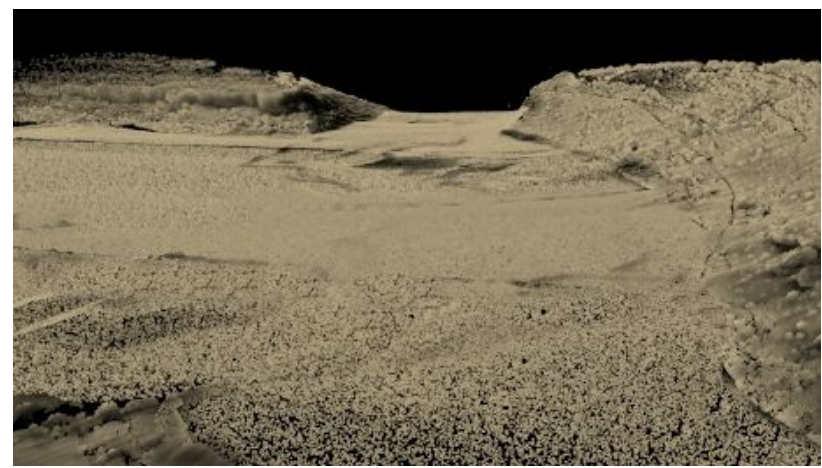

Figure 10. Landscape reconstruction in Site \#II at time of the terraces construction, 2,000 BP.

north. Our analysis show that the fluvial terrace at the time of construction was nearly leveled. Therefore, for the reconstruction, a leveled planar surface was created beginning at the valley and ending at the foothill. It was then modified according to the remaining topography, while preserving smoothness.

Site \#II presented a more complex environment. Nonetheless, by documenting the top of the fluvial terraces we can conclude that the slope of the terrace was gentle and did not exceed $0.5^{\circ}$. For the reconstruction, cut-planes were constructed between each two terraces, beginning from the lowermost. A local reference coordinate system was constructed so that the $\mathrm{X}$-axis is defined along the lower wall of the terrace, while the Y-axis points to the direction of the upper wall. This way, the remaining topography was always lower, and "new" sediments were gradually peeled-off. The reconstructed topography was created per terrace, by delineating a closed spline along the foothills that surround the site and along the remaining topography. To achieve smoothness and gradual slope change, the whole site was eventually reconstructed by a convex hull of the terraces' splines, which was then converted into a mesh (Fig. 10). As in Site \#I, small modifications were carried to accommodate the remaining topography.

\subsection{Time of abandonment}

We reconstruct the plots at time of abandonment according to the current state of the plots and their walls. As runoff used for irrigation was loaded with eroded loess sediments transported from relics of loessic sections on the upper basin of the Avdat tributary, substantial quantities of sediments were trapped within the agricultural terraces, leading to their gradual, yet leveled, siltation. Therefore, reconstruction of the landscape itself is carried at each terrace, while ensuring leveled surfaces. As analysis shows that the walls are positioned linearly, complete parts of the wall are copied and positioned in a straight line connecting the walls on both sides (Fig. 11).

\section{CONCLUSIONS AND FUTURE WORK}

Historical reconstruction of sites that underwent colossal destruction is a challenge, and such is the case with agricultural heritage sites, where erosion removed both infrastructure and soil. We studied in this paper various level of details that can be achieved in the examining ancient agricultural heritage, via the combination of terrestrial laser scans and photogrammetry based modeling. The level of detail describe is new, as study of such installations was limited. The detailed study into the construction of the terraces and their maintenance, in conjunction

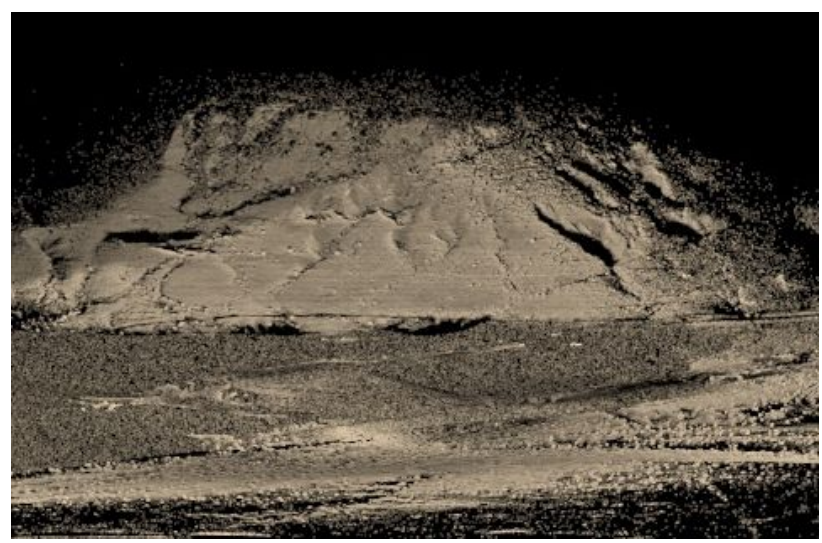

Figure 11. Complete reconstruction in of Site \#I at time of abandonment.

with the reconstruction of the topography, promotes insights into the lives of the Byzantine farmers. Considerations concerning the topography, soil, and runoff can be inferred either to their decision for specific locations of the terraces, or to the reasons of abandonment. Furthermore, by investigation of the walls community related topics can be discussed and further analyzed. Additionally, the insights gained by soil erosion affected sites versus intact ones offers value in developing methods and strategies to protect these historic installations.

\section{ACKNOWLEDGEMENTS}

The authors would like to thank Borislav Petrov from AWS Thinkbox for his support with the Krakatoa plugin. Our thanks are also due to Shai Madmon and Itamar Adi for their assistance in the topographic modeling.

\section{REFERENCES}

Arav, R., Filin, S., Avner, U., Bar-Oz, G., Nachmias, A., Malkinson, D., Nadel, D., 2015. High-resolution documentation, 3-D modeling and analysis of "desert kites". Journal of Archaeological Science, 57, pp. 302-314.

Avni, G., Porat, N., Avni, Y., 2013. Byzantine-Early Islamic agricultural systems in the Negev Highlands: Stages of development as interpreted through OSL dating. Journal of Field Archaeology, 38(4), pp. 332-346.

Avni, Y., Avni, G., Porat, N., 2019. A review of the rise and fall of ancient desert runoff agriculture in the Negev Highlands - A model for the southern Levant deserts. Journal of Arid Environments, 163, pp. 127-137.

Avni, Y., Porat, N., Avni, G., 2012. Pre-farming environment and OSL chronology in the Negev Highlands, Israel. Journal of Arid Environments, 86, pp. 12-27.

Avni, Y., Porat, N., Plakht, J., Avni, G., 2006. Geomorphic changes leading to natural desertification versus anthropogenic land conservation in an arid environment, the Negev Highlands, Israel. Geomorphology, 82(3-4), 177-200ppp.

Faershtein, G., Porat, N., Avni, Y., Matmon, A., 2016. Aggradation-incision transition in arid environments at the end of the Pleistocene: An example from the Negev Highlands, southern Israel. Geomorphology, 253, pp. 289-304. 
Haiman, M., 2012. Dating the agricultural terraces in the southern Levantine deserts-The spatial-contextual argument. Journal of Arid Environments, 86, pp. 43-49.

Londoño, A. C., Williams, P. R., Hart, M. L., 2017. A change in landscape: Lessons learned from abandonment of ancient Wari agricultural terraces in Southern Peru. Journal of Environmental Management, 202, pp. 532-542.

Pix4D S.A., 2019. Pix4D. Version: 4.2.27.

UNESCO, 2013. Periodic report - section ii-incense route desert cities in the negev. Technical report, World Heritage Center.

Zweig, R., Filin, S., Avni, Y., Sagy, A., Mushkin, A., 2018. Land degradation and gully development in arid environments deduced by mezzo- and micro-scale 3-D quantification - The Negev Highlands as a case study. Journal of Arid Environments, 153 , pp. 52-65. 